\title{
FILOSOFIA DA LIBERTAÇÃO: UM OLHAR SOBRE OS CONCEITOS DE CRISE E DESENVOLVIMENTO
}

\author{
KLÉDSON TIAGO ALVES DE SOUZA ${ }^{1}$ E JOSÉ FRANCISCO DAS \\ CHAGAS DE SOUZA ${ }^{2}$
}

\begin{abstract}
RESUMO: Este artigo tem por objetivo refletir, partindo dos conceitos de crise e desenvolvimento, sobre a filosofia da libertação, nascida na América Latina por volta dos anos 70, como um sinal de superação da estrutura colonizadora e opressora. O processo de construção de uma sociedade justa passa pela descolonização, daí que é preciso entender a crise como esse momento de mudança, e a filosofia da libertação como o movimento do pensamento que é capaz de promover aquilo que Dussel chama de primavera política.
\end{abstract}

PALAVRAS-CHAVE: Crise. Desenvolvimento. Filosofia da Libertação. América Latina.

ABSTRACT: This article seeks to reflect, considering the concepts of crisis and development, on the Philosophy of Liberation, created in Latin America around the 70s, as a sign of overcoming the colonizing and oppressive structure. The process of building a just society goes through decolonization, hence it is necessary to understand crisis as a moment of change and Philosophy of Liberation as a movement of thought capable of promoting what Dussel calls a political spring.

KEYWORDS: Crisis. Development. Philosophy of Liberation. Latin America.

Hodiernamente o conceito que mais emerge nas sociedades e nos cenários acadêmicos e populares, em suas mais diversas linguagens, é o de crise $^{3}$. Crise política, ética, econômica, ecológica, judiciária, moral, entre outras. Ao que parece, o mundo não tem saída. A crise tomou

\footnotetext{
${ }^{1}$ Mestrado em Filosofia pela Universidade Federal da Paraíba (UFPB). Membro do Conselho Editorial da Revista Trilhas Filosóficas - Publicação do Curso de Filosofia do Campus Caicó/UERN, do Grupo de Pesquisa Filosofia e Educação (UERN). Professor Substituto do Departamento de Filosofia do Campus Caicó da Universidade do Estado do Rio Grande do Norte. Tem experiência na área de Filosofia, com ênfase em Filosofia Medieval..E-mail: magal.ic@ hotmail.com.

2 Professor da Universidade do Estado do Rio Grande do Norte (UERN). Vice-líder do Núcleo de Estudos em Fenomenologia, Hermenêutica e Mística da UERN/Campus Caicó. Doutor em Letras pela Universidade Estadual do Rio Grande do Norte (UERN). E-mail: dedasouza1 @ gmail.com.

${ }^{3}$ Crise deverá ser entendida aqui em seu aspecto natural, como: a) Mudança de rota; b) Manifestação forte de superação; c) Instante na história de vulnerabilidade (risco), ruptura de sequência; d) Adaptação-reação; e) Gravidez: das crises sempre podem nascer, surgir algo novo; f) Crescimento, perda = temporário. A crise é parte da elaboração dialética da história - que se comporta como movimento cíclico, numa perspectiva hegeliana: dialética negativa. Isso é visto também, nessa mesma perspectiva, na Filosofia da Ciência, a partir dos autores Karl Popper e Thomas Kuhn. Ora, este último chega a apontar a crise como um momento de superação de um paradigma por outro ou sua manutenção mediante respostas dadas às anomalias surgidas no processo da ciência. Assim, a precisão que queremos dar ao conceito de crise neste trabalho é o de instante nevrálgico de transformação ou manutenção social.
} 
conta de todas as instâncias da natureza. Está o mundo na iminência do caos? Seria possível pensar modos ou alternativas de se enxergar a realidade posta? Ou a presente realidade seria um ponto de partida para uma nova realidade que exige novas posturas? Suscitando questões como estas, apontamos já a direção que se quer seguir: a crise como realidade dada e a busca de alternativas de como superá-la. Essa é uma questão que, a partir de conceitos advindos da filosofia da libertação de Enrique Dussel, pode-se pensar de modo mais acurado e paulatinamente vislumbrar uma discussão em que a libertação possa ser sinal de esperança em meio ao mar revolto da crise. Mas o fato positivo de se falar ou de se estar é o suscitar a pergunta pelo futuro histórico (KOSELLECK, 1999), isto é, o que esperar do que advém da crise. A primeira coisa a se perguntar, então, é: o que é crise?

Há um outro conceito que emergiu pós-segunda guerra mundial que foi o de "desenvolvimento". O desenvolvimento pode suscitar duas perspectivas: a primeira, a partir da lógica do capital, alicerçado sob a ideia de "progresso"; a segunda, a partir da noção de evolução da humanidade. E aqui caberia o viés de uma ética da libertação dusseliana: como superação do irracional em que o sujeito (cogito) moderno se predispõe como aquele EU egocêntrico a determinar o que o OUTRO deve ser. Daí a exclusão social. Está posto um problema da "alteridade" na elaboração do ser excluído a clamar: eu sou. A questão do SER e do NÃO SER - eurocentrismo ou americanismo. Mas, por acreditar que a libertação terá que ser integral, i. e, capaz de não ser excludente, mas pautada no respeito à vida, à dignidade humana e à concepção de pessoa, precisamos refletir também o referido conceito de desenvolvimento, estando ele emparelhado ao conceito de crise. O texto aqui não é contrário ao desenvolvimento em si, o que não se defende é, em nome do modelo desenvolvimentista criado pelo capitalismo, não respeitar o homem e o mundo. Há uma exploração do lucro pelo lucro. Esse modo de desenvolvimento já está saturado do ponto de vista de preservação da ética e da vida humana. O modelo de capitalismo está falido ${ }^{4}$ no mundo por se tratar de um modelo de concentração de riquezas para poucas pessoas, permitindo que uma massa sobrante ${ }^{5}$ esteja a sobreviver na periferia do mundo apenas com os resquícios do sistema. Além disso, as consequências negativas do

\footnotetext{
${ }^{4}$ Leonardo Boff (2016, p. 610-611) apresentou uma tese assaz interessante que traz a crise do capitalismo não como conjuntural nem estrutural, mas terminal. Para tal apresenta duas razões: "A primeira é a seguinte: a crise é terminal porque todos nós, mas particularmente, o capitalismo, encostamos na Terra. Ocupamos, depredando todo o planeta, desfazendo seu sutil equilíbrio e exaurindo excessivamente seus bens e serviços a ponto de ele não conseguir, sozinho, repor o que lhes foi sequestrado. [...] A segunda razão está ligada à crise humanitária que o capitalismo está gerando. Antes se restringia aos países periféricos. Hoje é global e atingiu os países centrais. Não se pode resolver a questão econômica desmontando a sociedade". Enfim, de modo particular o autor levanta as questões da natureza e humana (trabalho) para dizer que o capitalismo está a destruí-los.

${ }^{5}$ O termo massa sobrante é refeito por Dussel (2000, p. 66) denominando de "humanidade sobrante" na obra Ética da libertação na idade da globalização e da exclusão.
} 
desenvolvimento em voga têm gerado também drásticas consequências ambientais, como o aquecimento global. Este conceito de desenvolvimento fora posto em múltiplas facetas e imposto por nações que se entendem como desenvolvidas. Claro, com essa afirmação não se quer negar o desejo humano de satisfação das necessidades e melhoras nas condições de vida, que percorre toda a história da humanidade. O que se quer dizer é que a institucionalização desse motus "desenvolvimento" fora proposta de forma explícita em 20 de janeiro de 1949 pelo então presidente reeleito dos E.U.A., Harry Truman, que definiu a maior parte do mundo como "áreas subdesenvolvidas" (ACOSTA, 2016). Ademais, muito se falou ao longo desse tempo sobre desenvolvimento, até se criando sobrenomes para o mesmo, a saber: econômico, social, ambiental, agrário, até chegar ao desenvolvimento humano. Contudo, ao que parece, não ficou claro o que seja desenvolvimento, ou, pelo menos, que tipo de desenvolvimento se pensou ao instituí-lo.

"Crise" e "desenvolvimento" são conceitos que, ao que parece, andaram juntos, no que diz respeito a um discurso de progresso político. Há um risco iminente nestes dois conceitos, que é o hiato provocado entre governo e sociedade. Isto é, pode-se negligenciar a pessoa humana e sua dignidade em prol de um "desenvolvimento" que vise meramente o lucro. Ou seja, estabelece-se uma relação de dominação ou colonização em que há um encobrimento do outro, como alertou Dussel (1993).

Desta forma, o que se pretende discutir neste artigo são os conceitos de "crise" e “desenvolvimento", bem como pensar a filosofia da libertação - nascida no chão da América Latina explorada - como um caminho possível à construção de novas sociedades que busquem construir uma proposta alternativa a essa economia selvagem que coloca o lucro (capital) acima dos seres.

\footnotetext{
${ }^{6}$ Truman, então presidente, assim se pronunciou em seu discurso de posse do Segundo mandato: "Fourth, we must embark on a bold new program for making the benefits of our scientific advances and industrial progress available for the improvement and growth of underdeveloped areas. More than half the people of the world are living in conditions approaching misery. Their food is inadequate. They are victims of disease. Their economic life is primitive and stagnant. Their poverty is a handicap and a threat both to them and to more prosperous areas". Disponível em: < https://www.trumanlibrary.org/whistlestop/50yr_archive/inagural20jan1949.htm>. Acesso em 20 de junho de 2017. Acerca desse discurso de Truman comentou o advogado e jornalista, então articulista da Opera Mundi, Max Altman: "Para os norte-americanos e mais amplamente para os ocidentais, o combate contra o 'subdesenvolvimento' seria o substituto da "missão civilizadora"' do tempo das colônias como objetivo messiânico. No meio século que se seguiu se tornaria corriqueiro não mais levar em conta as nações e os povos em sua diversidade cultural, social e humana, mas somente e sim em catalogá-los como 'Opaís subdesenvolvido' e 'país desenvolvido' em função do Produto Interno Bruto por habitante (PIB/habitante). Era o triunfo da econometria, uma visão contábil e matemática da economia". Disponível em: < http://operamundi.uol.com.br/conteudo/historia/33527/hoje+na+historia+1949++surge+a+expressao+subdesenvolvimento.shtml\#>. Acesso em 20 de junho de 2017.
} 


\section{Crise e desenvolvimento}

O conceito de "crise" é muito amplo. Pode-se falar de crise política, econômica, social, moral, existencial e tantas outras. O conceito deriva do grego Krisis, que traz a perspectiva de ser um juízo. Deriva, assim, do verbo kríno que significa julgar, decidir. Outra origem vem do latim que aponta Crisis como separação.

A primeira perspectiva de crise surge, ao que perece, com Hipócrates (460 a.C. - 370 a.C) numa perspectiva médica. Este tomava o conceito como indicação de transformação decisiva que ocorria no ponto culminante de uma doença, e nisto orientava seu curso, seja em sentido favorável ou não. Essa ideia não é propriamente a que se quer usar aqui, contudo, se pode refletir em cima desse conceito a partir dessa noção de transformação ou superação ${ }^{7}$, isto é, a crise como um momento de passagem de algo que pode ser danoso a algo novo que não se sabe se será bom ou ruim, algo semelhante ao que aponta Saint-Simon (1807-1808) em sua obra Introdução aos trabalhos científicos do século XIX, quando pensa que o progresso necessário da história é dominado por uma lei geral que determina a sucessão de épocas orgânicas e de épocas críticas (SAINT-SIMON, 1977).

Se "crise", num sentido mais amplo, teve sua origem na medicina no século IV a.C. com Hipócrates, será entre os séculos XVII e XVIII que surgirá a ideia de crise econômica, ainda que de forma generalizada. Não obstante, é no século XIX, com a virada epistemológica provocada por Marx, que colocou a filosofia com os pés no chão ${ }^{8}$, que se teve o conceito de crise econômica melhor significado. O porquê de se destacar tal análise do conceito de crise é pelo modo da verificação das rupturas que existem dentro do modelo econômico da época, isto é, o ainda tão atual capitalismo, em que há bruscas desarticulações do equilíbrio global entre as esferas da produção e do consumo. O pano de fundo do capitalismo é o lucro, como bem observa Karl Marx em seu Manuscritos econômicos e filosóficos. A primeira coisa que o autor aponta é a diferença entre salário e lucro:

O lucro ou ganho do capital é inteiramente diferente do salário [proveniente] do trabalho (Arbeitslohn). Esta diversidade manifesta-se de um modo duplo. Por um lado, os ganhos do capital regulam-se totalmente pelo valor do capital aplicado, mesmo que o trabalho de controle e direção possa ser o mesmo junto

\footnotetext{
${ }^{7}$ É assaz interessante a perspectiva de passagem. A crise como passagem de um tempo a outro: "La rigueur ou l'uniformité philosophique n'était pas nécessaire. On pouvait se représenter les crises comme des transitions entre les phases d'un cycle mais aussi dans le cadre d'une conception « horizontale » du devenir historique : dans l'un et l'autre cas, un historien pouvait contester les interprétations d'un autre historien tout comme un médecin peut s'inscrire en faux contre le diagnostic d'un de ses collègues" (STARN, 1976, p. 6).

${ }^{8}$ Cf. ENGELS (2012, p. 151).
} 
a capitais diversos. Além disso, some-se que, em grandes fábricas, este trabalho é todo confiado a um funcionário principal (hauptcommis), cujo ordenado (Gehalt) não tem relação alguma com o capital cuja gestão ele controla. Ainda que o trabalho do proprietário se reduza aqui a quase nada, ele exige ainda lucros, na proporção de seu capital (MARX, 2008, p. 40-41).

Marx ainda irá tratar de modo mais profundo acerca da problemática do lucro nesta mesma obra, até o momento em que se chega ao trabalho estranhado, isto é, quando o trabalhador não reconhece o fruto do seu trabalho. Mas, essa problemática não é objeto deste texto. Traz-se esse assunto como suporte para mostrar a relação entre crise e capitalismo. Claro, a questão do lucro é uma perspectiva de crise, ou poder-se-ia dizer que é por meio do lucro que se chega ao efeito colateral ou resultado do capitalismo, a saber, a desigualdade social.

Há dois autores que podem contribuir nessa perspectiva de entender a relação entre crise e capitalismo. Kautsky (1978) cria que a causa das crises no capitalismo era o subconsumo das massas frente a uma escala de produção sempre ascendente. Hilferding (1985), por sua vez, acreditava que a causa era a ausência de um planejamento racional que organizasse a produção social de acordo com as necessidades de consumo da sociedade. De certa forma, o que percebemos é que na estrutura do próprio capitalismo há uma crise permanente, pois ele cria um hiato entre classe dominante (que detém os meios de produção e a concentração do capital) e a classe trabalhadora (que vende sua força de trabalho). Uma estrutura política e econômica que causa esse tipo de relação tem, em si, fervilhando, uma crise. Agora, por que esse problema ainda não teve grandes impactos na luta de uma classe oprimida contra a opressora? Justamente porque esta criou o discurso do desenvolvimento para ludibriar ou demonstrar falsamente uma preocupação com aquela. $\mathrm{O}$ discurso bem elaborado concentra as razões do poder. $\mathrm{O}$ uso de uma linguagem que cria necessidades e nos torna infelizes estando fora do processo. A linguagem que sustenta o discurso do opressor ainda é o grande trunfo que é parte intrínseca ao capitalismo até nossos dias. Não somente um discurso por parte do opressor, mas seu poder de cooptar e inculcar na mente do oprimido a repetição dessa linguagem criada pelos representantes do grande capital. O discurso repetido, ecoado pelos que deveriam e poderiam não só contestá-lo como fazer ouvir um outro discurso de quem exige pensar a partir de si (do outro como sujeito sendo ele mesmo) e não fortalecer a fala do sujeito (como outro diferente de si). E isto demonstra que não somos iguais, que a fissura ou fissuras estão na sociedade, reclamando que tenhamos ciência "do lugar" ou do "chão" onde estamos. Só assim poderemos pensar numa alternativa à crise, ao desenvolvimento: sabendo o que somos para evocar (lutar) 
pela libertação de tantos grilhões a impedir ao homem e a mulher se realizarem enquanto seres. O conceito de libertação passa por esta tomada de consciência de si e do lugar onde estamos.

O segundo conceito que se aborda aqui é o de "desenvolvimento", que encontra-se atrelado ao capitalismo, este que no intuito de se instaurar o promete sem explicitar o que isso significa, ou pelo menos, sem dizer claramente sobre o desenvolvimento de quem se baseia a sua promessa, isto é, qual o público beneficiário desse projeto; não diz também quais são os efeitos desse desenvolvimento. Como assinala Acosta:

Se a ideia de desenvolvimento está em crise 'em nossa paisagem intelectual', necessariamente devemos questionar também o conceito de progresso, que emergiu com força há uns quinhentos anos na Europa. Os elementos substanciais da visão dominante imposta pelo desenvolvimento nutrem-se dos valores impostos pelo progresso civilizatório europeu, extremamente expansionista, influente e destrutivo. (ACOSTA, 2016, p. 54-55)

Com esse apontamento de Acosta surge mais um conceito a ser pensado, não de forma separada, mas imbricada à ideia de desenvolvimento, que é o conceito de progresso. Assim, a própria promessa do desenvolvimento entra em crise consigo mesmo, primeiro por não se ter uma identidade, depois por não gerar qualidade de vida, e sim alto índice de desigualdade social. O que torna o desenvolvimento totalmente contraditório, pois promete algo, e seu efeito é o contrário. Eis novamente o poder do discurso como verbo dominador da classe oprimida. Essa ideia de progresso nasce com o mundo europeu querendo desbravar e colonizar novas terras, fontes de riquezas para si, como bem afirma Galeano (2014, p. 38): “Com tiros de arcabuz, golpes de espada e hálitos de peste, acometiam os escassos e implacáveis conquistadores da América”. Em nome do progresso e do desenvolvimento acabou-se por encobrir a figura do outro, como denuncia Enrique Dussel:

Mas 'nasceu' quando a Europa pôde se confrontar com o seu 'Outro' e controlálo, vencê-lo, violentá-lo: quando pôde se definir como um 'ego' descobridor, conquistador, colonizador da Alteridade constitutiva da própria modernidade. [...] esse Outro não foi 'descoberto' como Outro, mas foi 'em-coberto' como o 'si-mesmo'. (DUSSEL, 1993, p. 8).

O Projeto de desenvolvimento troca o homem pelo capital, pelo lucro. Assim, se pensa em desenvolvimento de alguns, enquanto outros padecem e sustentam o alto padrão de quem o promete. “[...] um não-tem-pão (isto é, deixa-o sem produto para consumir, por pobreza ou porque lhe roubam o fruto do seu trabalho) ou um 'analfabeto' [...] diante de um "não-tem- 
livros" (pois não os pode comprar) ou de uma cultura que não tem condições de se expressar" (DUSSEL, 1995, p. 22). É preciso pensar a partir de uma estrutura diferente. Construir algo novo que promova a libertação, que saia do campo meramente ideal e parta para a transformação da realidade, que tenha como centro do debate o excluído, o oprimido, o pobre. Assim, o ponto de partida para se pensar numa outra estrutura de sociedade e que é a precisão do que entendemos como libertação é a "exclusão do outro, [...] da interpelação feita a nós pelo Outro e como resposta a ela, a afirmação do Outro enquanto outro" (DUSSEL, 1995, p. 23). Isso se caracteriza como a negação da negação que foi imposta aos oprimidos e oprimidas. Vázquez (2011) aponta o caminho marxiano do homem para a devida mudança:

Com Marx, o problema da práxis como atividade humana transformadora da natureza e da sociedade passa para o primeiro plano. A filosofia se torna consciência, fundamento teórico e seu instrumento. A relação entre teoria e práxis é para Marx teórica e prática: prática, na medida em que a teoria, como guia da ação, molda a atividade do homem, particularmente a atividade revolucionária; teórica, na medida em que esta relação é consciente (SÁNCHEZ VÁSQUEZ, 2011. p. 111).

O que Marx pretende é ver o homem como atividade sensível. É ver o homem como mescla de teoria e práxis, tendo a vida real, ou a prática, como fundamento constitutivo da teoria, e não o inverso, daí a tese XI ad Feuerbach: "Os filósofos só interpretaram o mundo de diferentes maneiras; do que se trata é transformá-lo" (MARX, 2007, p. 103, grifo do autor). A transformação só acontece se se voltar para o material. Esse debate da transformação presente em Marx dialoga e fundamenta a Filosofia da Libertação de Dussel. Pois está no bojo hermenêutico e fenomenológico da filosofia produzida na América Latina a transformação real do sistema de opressão que lhe é imposto. Resta a questão: como fazer tal transformação? Ou ainda, como se promover a libertação dessa ideia de desenvolvimento e progresso?

\section{A Filosofia da Libertação9 em Enrique Dussel}

\footnotetext{
${ }^{9}$ MANCE, 2000, p. 26, grifo do autor: "Diferentes conceitos de libertação aparecem na história da filosofia associados a conceitos de emancipação e liberdade. É, geralmente, no campo da ética e da filosofia política que emergem determinados problemas em que tais conceitos - especialmente os dois últimos - são considerados no desenvolvimento de reflexões sobre a convivência humana, suas possibilidades e limites. Embora não seja possível isolar cabalmente a noção de liberdade da noção de libertação, conquanto se possa distingui-las, apenas recentemente - nos últimos trinta anos - o conceito de libertação tem sido filosoficamente tematizado em sua complexidade. Em tal processo de tematização acabou por emergir as, assim chamadas, Filosofias de Libertação, que não apenas consideraram a libertação em seu aspecto negativo, isto é, a libertação de impedimentos ou cerceamentos ao exercício satisfatório da liberdade, quanto positivamente, isto é, a libertação para a realização das valiosas singularidades humanas em sua criativa diversidade".
} 
Pensar a partir da filosofia de Dussel é fazer o esforço de descentralizar a Europa. Dussel promove uma releitura dos textos de Marx e de Lévinas a partir de sua vivência latinoamericana. No âmbito da filosofia da libertação aparecem três caminhos paradigmáticos, a saber: o caminho da ética da libertação, de uma política de libertação e de uma economia de libertação.

O centro ético da filosofia da libertação que Dussel propõe é o apropriamento da concepção do outro como outro (outridade, alteridade, intersubjetividade), isto é, do outro em sua dignidade, conceito pensado a partir de Lévinas. Sezyshta $(2014$, p. 22) traz a noção de exterioridade como "[...] o âmbito próprio do outro, do outro homem que não pode ser incluído ou reduzido ao Mesmo. Trata-se do Outro livre em seu ser distinto, em sua palavra, em seu dizer que se encontra sempre para além do mundo, do sistema e de toda representação". Pensar uma ética a partir do outro é pensar a relação. O outro deixa seu lugar de mero sujeito (isto é, deixa a sujeição) e assume um espaço que lhe é digno, e aquele que se propõe ir ao encontro do outro deixa de ser para si e passa a ser um "si mesmo" para o outro.

A filosofia da libertação definida por Dussel como “[...] um saber teórico articulado à práxis de libertação dos oprimidos [...]" (DUSSEL, 1977, p. 247) é o canal pelo qual se faz o exercício de ouvir o outro: "O saber-ouvir é o momento constitutivo do método mesmo; é o momento discipular do filosofar; é a condição de possibilidade do saber-interpretar para saberservir"10 (DUSSEL, 1973, p. 126). Destarte, Filosofia da Libertação é a epifania do oprimido ${ }^{11}$. A opção pela vítima é levada a rigor, pois qualquer Estado que produza vítimas é tido como antiético e a filosofia da libertação sai em defesa do vitimado e da vitimada. Aquele carente de SER "grita". O eco desta voz não pode ser deixado de lado. Quem grita pede socorro a partir do não-ser. Se não há essa manifestação do oprimido, a libertação torna-se apenas o desejo intelectual de alguém que fala pelo outro. Não há que omitir-se, seja o oprimido, seja aquele que tem consciência da desigualdade e também clama pela libertação humana dos grilhões do capital. Ninguém poderá omitir-se em não querer ouvir. Além disso, Dussel (1995, p. 18-19) mostra, inspirado em Lévinas, a filosofia da libertação como descoberta do movimento de opressão:

Porque a experiência inicial da Filosofia da Libertação consiste em descobrir o 'fato' opressivo da dominação, em que sujeitos se constituem 'senhores' de

\footnotetext{
${ }^{10}$ DUSSEL, 1973, p. 126: "El saber-oír es el momento constitutivo del método mismo; es el momento discipular del filosofar; es la condición de posibilidad del saber-interpretar para saber-servir (la erótica, la pedagógica, la política, la teoló-gica)"

${ }^{11}$ Cf. DUSSEL, 1977, p. 22
} 
outros sujeitos, no plano mundial (desde o início da expansão europeia em 1942; fato constitutivo que deu origem à 'modernidade'), Centro-Periferia; no plano nacional (elites-massas, burguesia nacional-classe operária e povo); no plano erótico (homem-mulher); no plano pedagógico (cultura imperial, elitista, versus cultura periférica, popular etc.); no plano religioso (o fetichismo em todos os níveis) etc... Esta 'experiência' inicial vivenciada por todo latino-americano, até mesmo nas aulas universitárias europeias de filosofia - expressaria melhor dentro da categoria 'Autrui' (outra pessoa trata como outro), como pauper (pobre). O pobre, o dominado, o índio massacrado, o negro escravo, o asiático das guerras do ópio, o judeu nos campos de concentração, a mulher objeto sexual, a criança sujeita a manipulações ideológicas (também a juventude, a cultura popular e o mercado subjugados pela publicidade) não conseguirão tomar como ponto de partida pura e simplesmente, a 'estima de si mesmo'. O oprimido, o torturado, o que vê ser destruída a sua carne sofredora, todos eles simplesmente gritam, clamando por justiça. (DUSSEL, 1995, p. 18-19, grifo do autor).

Nesse sentido, a filosofia da libertação é preponderantemente uma filosofia da vida, ou melhor, uma filosofia da vida a partir da vítima, do oprimido. A política que foi aplicada na América Latina se constituiu com o prisma da colonização, da opressão, da exploração do povo pobre ${ }^{12}$. Assim, o "grito" de resistência desse povo, que faz com que ele saia do não-ser para o ser, é a libertação, que é a tomada de consciência de se estar envolto num sistema de opressão que nega a outridade.

Em nível global ao longo da história se percebe a invasão dos europeus ao continente postulado como Novo Mundo, e desse mundo sugaram todas as riquezas: "o ouro dos índios e as carnes dos escravos negros" (DUSSEL, 1977, p. 63). Nesta perspectiva, parece que as grandes riquezas tanto eurocêntricas quanto americanas (dos E.U.A.) são frutos de muita dominação e colonização.

O princípio ético da libertação em muito assemelha-se com a última tese contra Feuerbach de Marx, pois ambos trazem a ideia de transformar o mundo. Ora, Dussel constrói seu pensamento ético-filosófico a partir do debate marxiano sobre a relação de trabalho que anula o oprimido no processo, pois o trabalhador sofre um ataque direto à sua dignidade quando na mais-valia objetiva (torna objeto) sua vida. Por isso que contrapondo a ética da realização

\footnotetext{
${ }^{12}$ Um exemplo que pode ser dado acerca dessa política que produz vítimas: se se olhar para a América percebe-se que há desde a máxima "a América para os americanos" anunciada através da Doutrina Monroe, em 1823, o espírito de dominação por parte dos Estados Unidos da América. Em 2017, se repete essa premissa no governo eleito, Donald Trump, afirmando a "américa para os americanos", e é preciso destacar algumas frases interessantes em que se apresenta o desejo de dominar: a) "Together we will determine the course of America and the world for many, many years to come", a determinação por parte dos E.U.A. que influencia em todo o mundo; b) "From this day forward, it's going to be only America first. America first", a ideia de que primeiro a América (os E.U.A. são, em primeiro lugar, um nacionalismo dominador); a partir desses dois trechos se percebe que o que permeia essa tese é o espírito de dominação, aquilo que já apontou Dussel em seu tempo (1988, p. 358): "A dependência é esta situação de dominação dentro do sistema mundial capitalista".
} 
do capital - que é a desrealização do trabalhador - Dussel sente a necessidade de uma alternativa que parta daquele que é tornado objeto. A ética da libertação se coloca como colaboradora no processo de crescimento do sujeito histórico, de forma a contribuir com a superação desse sistema de opressão. Assim, é o não encobrimento desse Outro. Após esse processo espera-se que se provoque uma emancipação "em uma moradia digna para todos, atingindo a autoconsciência, a consciência de suas estruturas culturais, de seus valores últimos, em identidade consigo mesmo" (SEZYSHTA, 2014, p. 30). O critério para se impor deste modo é só um: libertar efetivamente a vítima, conferindo-lhe dignidade. O comprometimento é com uma práxis de libertação.

Dussel tem claramente em seus textos uma opção radical pela vítima. Essa vítima ou comunidade de vítimas representa “[...] seres humanos que não podem reproduzir ou desenvolver sua vida, que foram excluídos da participação da discussão, que são afetados por alguma situação de morte" (DUSSEL, 2000, p. 303). Sezyshta (2014, p. 98) aponta para a questão cerne que a partir de Dussel (2001) se pode fazer hoje: “é possível uma nova política, outra política, uma anti-política que se origina na práxis emancipadora que parte da responsabilidade pelo Outro?". A questão é uma provocação a pensar uma filosofia crítica que aponte as falhas do sistema no sentido de tentar superá-las para promover uma dignidade harmônica entre natureza e homem.

O processo de construção de uma sociedade justa passa pela necessidade de descolonização. Quando uma nação começa a pensar esse aspecto acontece o que Dussel chama de "primavera política" civilização que saia dos moldes dominadores eurocêntricos e imperialistas, como é o caso dos E.U.A., é pensar em algo que seja trans-moderno e trans-capitalista. Dussel (2007) corrige a expressão trágica de Schopenhauer, Nietzsche e Heidegger, da ideia de vontade-de-poder, pois ele vê que essa vontade é muito mais de viver, é vontade-de-vida. O filósofo do exílio afirma

\footnotetext{
${ }^{13}$ Sezyshta (2014, p. 100, n. 77) consegue sintetizar bem essa ideia de Dussel que "chama de primavera política o que tem ocorrido em vários países da América Latina, a partir da emergência dos povos indígenas, das centenas de movimentos sociais novos que têm se reunido no Fórum Social Mundial e nos mais recentes processos eleitorais, que culminaram com a eleição de presidentes considerados mais à esquerda, sobretudo de um operário no Brasil e de um indígena na Bolívia. Em Conferência intitulada 'Vivemos uma primavera política', proferida em 20.11.2006 - nas Jornadas Bolivarianas/terceira edição - UFSC/ Florianópolis/ Brasil, disse Dussel: 'esse momento Latino-americano é um momento forte, e eu diria que se está produzindo uma primavera política. Há um certo amadurecimento, desde baixo, dos povos latino-americanos excluídos que, em todas as partes, começam a ter uma certa autoria. (...) Algo novo está acontecendo na América Latina e por isso necessitamos conceituar as categorias fundamentais da política"'. Diferentemente de hoje que, ao que se constata, na América Latina vive-se uma "virada à direita", em que os direitos sociais estão sendo violados e populações voltam a viver vizinhadas à fome e à miséria. De modo particular, o Brasil hoje está sob um governo de extrema-direita que constantemente retira direitos e vende o país, ao modo entreguista; se submete como serviçal ao governo de $\mathrm{D}$. Trump, presidente dos E.U.A.
} 
que "na modernidade eurocêntrica, da invasão e da posterior conquista da América em 1492, o pensamento político definiu em geral poder como dominação" (DUSSEL, 2007, p. 25). Se se elimina essa noção de poder como dominação e se dá mais ênfase à ideia de vontade-de-viver isso se torna potência que pode mover, impulsionar e arrastar à valorização da vida, evitando a morte.

Essa determinação de vontade-de-vida concerne em si o aspecto material fundamental da definição de poder político: "a política é uma atividade que organiza e promove a produção, reprodução e aumento da vida de seus membros" (DUSSEL, 2007, p. 26). Isso se diz porque, de fato, já está subentendido nessa premissa a ideia de bem comum que é a base de todo poder político, já que este está sempre com o povo. É no consenso que está a força do poder político:

O consenso deve ser um acordo de todos os participantes, como sujeitos livres, autônomos, racionais, com igual capacidade de intervenção retórica, para que a solidez da união das vontades tenha consistência para resistir aos ataques e criar as instituições que lhe dêem permanência e governabilidade. (DUSSEL, 2007, p. 27)

É o povo quem dá condições de governabilidade, isto é, o poder está no povo e não no governo, tendo em vista que "o poder é uma faculdade, uma capacidade, que se tem ou não se tem, mas com precisão nunca se toma" (DUSSEL, 2007, p. 31). O povo delega esse poder a um representante que deve obediência a este mesmo povo que o colocou no governo, este movimento é o que Dussel caracteriza como poder obediencial: "o que manda é o representante que deve cumprir uma função da potesta. É eleito para exercer delegadamente o poder da comunidade; deve fazê-lo em função das exigências, reivindicações, necessidades da comunidade" (DUSSEL, 2007, p. 39, grifo do autor). Potentia é o poder que a comunidade detém como capacidade ou faculdade que lhe é inerente. Potesta é a institucionalização do poder do povo. A pretensão daquele que se coloca como delegado pelo povo deve ser a de promover a justiça para que se obtenha a felicidade empírica possível de uma comunidade política, de um povo. Então, essa relação de poder se constitui da seguinte forma: a comunidade tem um poder que lhe é inerente (potentia), e delega este poder a um ou uma representante; no momento em que delega, este poder delegado (potesta) passa a dever uma obediência de onde lhe é emanado, essa ligação é o que Dussel denomina como poder obediencial. 


\section{Considerações finais}

Tratamos aqui, não de forma esgotada - porque o assunto é de uma amplitude tal que o artigo não dá conta de encerrá-lo em si de crise, desenvolvimento e Filosofia da Libertação. Das duas primeiras e em nome destas eclode a necessidade da terceira. Como? Pelo viés no qual se estrutura a busca pelo desenvolvimento das nações, este está atrelado ao devir do capital que fomenta a necessidade do consumo associado à ideia de felicidade de realização humana. Por sua vez, a forma como o capitalismo se edifica cria uma legião de excluídos que não usufruem de sua produção. Esta legião é quem mais fortalece o acúmulo das riquezas concentradas nas mãos de poucos. Por ser a maioria, renegada a esta condição, torna-se fundamental como a mão de obra barata a subsidiar a riqueza dos que já a detêm. Mas, não somente este aspecto. Pelo lado dos detentores do capital, boa parte destes nem sequer produzem nada e não precisam produzir coisa alguma, e mesmo assim, ganham com as especulações de investimentos em modalidades alheias à questão humana. A crise tem suas raízes no interior do próprio capitalismo. Como ela, o capitalismo não resolveu o problema do planeta na sua forma mais global porque é excludente. Ao fazer isso gera uma massa sobrante que pode se rebelar contra o próprio sistema que os rejeita. Dessarte, não há como se pensar num desenvolvimento pautado no progresso das nações quando este não consegue e não quer incluir a todos e todas no processo. Disso, fatalmente recai sobre a crise, enquanto ruptura.

Chamamos de consciência ética a capacidade que se tem de escutar a voz do outro, palavra transontológica que irrompe de além do sistema vigente. É possível que o justo protesto do outro ponha em questão os princípios morais do sistema. Somente quem tem consciência ética pode aceitar o questionamento a partir do critério absoluto: o outro como outro na justiça. (DUSSEL, 1977, p. 65).

Bom dizer que sobre a Filosofia da Libertação, mesmo sendo uma reflexão recente, é necessário remontar a todo um processo histórico e geopolítico de colonização pelo qual foi submetido o caso específico da América Latina. Sem omitir que o desejo libertador se faz presente não só na América Latina espoliada desde 1459, mas, inclui na mesma perspectiva outras regiões que foram feitas periféricas em dimensões planetárias. Destacamos a América Latina por vivermos nela, mas a reflexão da libertação terá que ser feita por todos aqueles que precisam serem ouvidos.

Dussel ainda fala de uma ética da libertação, refletido de maneira filosófica e aponta para uma consequência da destruição do mundo e do homem em nível planetário. 
A ética da libertação reflete filosoficamente a partir deste horizonte planetário do sistema-mundo; a partir deste duplo limite que configura uma crise terminal de um processo civilizatório: a destruição ecológica da vida no planeta e a extinção da própria vida humana na miséria e na fome da maioria da humanidade. (DUSSEL, 2002, p. 66).

Portanto, é possível olharmos para a crise como esse momento de superação de velhas estruturas opressoras e excludentes, bem como superarmos o discurso alienante do desenvolvimento que apenas aumenta o hiato entre os oprimidos e os opressores, passando a ser usado apenas para ludibriar e enganar a grande massa; assim, podemos vislumbrar uma outra proposta que as supere a partir do prisma da descolonização das mentes, com uma práxis libertadora em que a potentia devidamente organizada seja capaz de proporcionar delegados comprometidos com o projeto de uma sociedade concretamente socialista, que é o projeto da filosofia da libertação.

\section{REFERÊNCIAS BIBLIOGRÁFICAS:}

ACOSTA, Alberto. O bem viver: uma oportunidade para imaginar outros mundos. Tradução de Tadeu Breda. São Paulo: Autonomia Literária, Elefante, 2016.

BOFF, Leonardo. Crise terminal do capitalismo. In: LÖWY, Michael. O marxismo na América Latina: uma antologia de 1909 aos dias atuais. Tradução de Cláudia Schilling, Luís Carlos Borges. 4. ed., ampl. - São Paulo: Expressão Popular : Perseu Abramo, 2016, p. 610-612.

DUSSEL, Enrique e et ali. Hacia uma filosofía de la liberación latinoamericana. Buenos Aires: Bonum, 1973

Filosofia da Libertação - na América Latina. São Paulo: Loyola, 1977.

Hacia um Marx desconocido: un comentario de los manuscritos del 61-63. México: Siglo XXI, 1988

1492: O Enconbrimento do Outro: a origem do mito da modernidade. Tradução Jaime A. Clasen. Petrópolis, RJ: Vozes, 1993.

Filosofia da Libertação: Crítica à ideologia da exclusão. Tradução Georges I. Maissiat. São Paulo: Paulus, 1995.

Hacia una filosofia política crítica. Bilbao: Desclèe, 2001.

13 Tesis de Economia Política (prelo), 2013.

Ética da libertação na idade da globalização e da exclusão. Petrópolis: Vozes, 2000.

20 Teses de Política. $1^{\text {a }}$ ed. São Paulo: Expressão Popular, 2007.

ENGELS, Friedrich. Ludwig Feuerbach e o fim da filosofia clássica alemã. In: Germinal: Marxismo e Educação em Debate, Salvador, v. 4, n. 2, p. 131-166, dez. 2012. 
GALEANO, E. H. As veias abertas da América Latina. Trad.: Sérgio Faraco. Porto Alegre: L\&PM, 2014.

HILFERDING, Rudolf. O capital financeiro. São Paulo: Nova Cultural: 1985.

MARX, K., Teses sobre Feuerbach. In: MARX, Karl; ENGELS, Friedrich. A ideologia alemã. $3^{\mathrm{a}}$ ed. São Paulo: Martins Fontes, 2007;

KAUTSKY, Karl Teorias de las crisis. In: Lucio Colleti (org.), El Marxismo y el "Derrumbe" del Capitalismo. Madrid, Siglo Veintiuno Editores, 1978.

KOSELLECK, Reinhart. Crítica e crise: uma contribuição à patogênese do mundo burgês. Tradução do original alemão [de Luciana Villas-Boas Castelo-Branco. Rio de Janeiro: Contraponto, 1999.

MANCE, Euclides André. Uma Introdução Conceitual às Filosofias de Libertação. In: Revista Libertação-Liberación / Nova Fase - Curitiba, IFiL, Ano 1, N.1, 2000, p.25-80. Disponível em: https://issuu.com/ricardo2p/docs/liberta o-liberaci_n_nova_fase. Acesso em 14 de julho de 2017.

MARX, Karl. Manuscrito Econômicos-Filosóficos. Tradução, Apresentação e Notas de Jesus Ranieri. São Paulo: Boitempo, 2008.

SAINT-SIMON, Claude-Henri de. Introduction a la philosophie du XIXe siècle. In: SAINTSIMON, C. de. Oeuvres complètes. Tome I. Genève: Slatkine Reprints/Éditions antropós, 1977.

SÁNCHEZ VÁZQUEZ, Adolfo. Filosofia da práxis. 2a ed., Buenos Aires: Consejo Latinoamericano de Ciencias Sociales - Clacso: São Paulo: Expressão Popular, Brasil, 2011.

SEZYSHTA, Arivaldo José. Corporalidade despida: da exterioridade marxiana à opção pela vítima em Enrique Dussel. João Pessoa, 2014. Tese de doutorado. Orientador: Dr. Antônio Rufino Vieira. Disponível em:

http://tede.biblioteca.ufpb.br/bitstream/tede/5643/1/arquivototal.pdf. Acesso em 12 de julho de 2017.

STARN, Randolph «Métamorphoses d'une notion», Communications, nº 25, 1976. 